\title{
The Experiences of the Elderly and Caregivers in Respect of Caring for the Elderly in Windhoek and Rehoboth Namibia: An Exploratory and Descriptive Study
}

\author{
Joan M. Kloppers*, Agnes van Dyk, Louise Pretorius \\ School of Nursing and Public Health, Faculty of Health Science, The University of Namibia, \\ Windhoek, Namibia \\ Email: ${ }^{*}$ jkloppers@unam.na
}

Received 8 March 2015; accepted 23 March 2015; published 27 March 2015

Copyright (C) 2015 by authors and Scientific Research Publishing Inc.

This work is licensed under the Creative Commons Attribution International License (CC BY). http://creativecommons.org/licenses/by/4.0/

\section{Abstract}

In many instances, care for the elderly, especially in long-term care institutions, is provided under minimal supervision by caregivers who are lay people. This can lead to poor quality care or neglect of the elderly. The research question was: "How competent are lay caregivers for the elderly in old age homes, who often lack the opportunity for training to improve their knowledge and skills, in delivering care to the elderly? The aims of the study were to explore and describe the experiences of both the caregivers and the elderly in respect of caring for the elderly in old age homes. The objectives of the study were to explore and describe the experiences of the caregivers and the elderly with respect to caring for the elderly and in respect of nursing care they received. A qualitative, explorative, descriptive, contextual and phenomenology design was used to perform this study. In the situational analysis, the experiences and needs of the caregivers were described. Themes in terms of interpersonal relationships that could be positive or negative regarding the elderly were identified. These included lack of regular in-service training sessions for caregivers. Likewise, sub-themes like communication, support and caring for elderly people were revealed. Inadequate knowledge of caregivers in caring procedures, a shortage of staff, equipment and absence of policies which should support and guide the work of caregivers impacts negatively on the care of the elderly. From the experiences of the elderly and caregivers, the competencies under scrutiny emerged and were measured qualitatively by the perceptions of the elderly, in respect of the caring they were exposed to.

\footnotetext{
${ }^{*}$ Corresponding author.
} 


\section{Keywords}

\section{Caregiver(s), Caring, Elderly, Experiences, Old Age Home}

\section{Introduction}

The number of elderly people has increased tremendously. Statistics in Namibia show that in 2001 there were 122,195 elderly people. According to [1], the Khomas Region, incorporating Windhoek as the capital city, had 8858 elderly people, which represented $7.2 \%$ of all elderly people in Namibia.

This, combined with the higher incidence of developing chronic diseases, and the normal biological changes that occur in the elderly' body, necessitates competent caregivers to care for them. According to [2] and [3], competency means having suitable and sufficient knowledge, qualifications and experience in the field that caregivers work. This enables them to understand the hazards and risks involved with the work, the operating environment, and the type of people they need to work with. They need sufficient training to be able to communicate the results of their assessment to all necessary persons (in writing if necessary) in a clear, understandable and comprehensive manner. Improvement in competencies of the caregiver can be obtained through communication and support, in order to strengthen their competencies and teach them new skills that will enhance patient safety. According to [4], caring for the elderly and listening attentively to what they say about themselves and their varied health situations, especially in relation to quality of life and peace of mind, body and soul, are important matters to persons aligned with caring for the elderly.

In Namibia, some caregivers have no training at all. They do the caring out of passion and what their parents have taught them. The Windhoek observer, a newspaper according to [5] comments that the Dean of the School of Medicine, Peter Nyrango, admitted that specialized training in the care of the elderly was lacking in the University of Namibia curriculum. The German academic exchange service will fund the initiative to introduce an accredited degree and post graduate programme on caring for the elderly. Reference [6] stated that in the United Kingdom as well as other countries hospitalization period was shorter. Family caregivers continue with the role of health professionals and usually they have no training.

As a result of all these factors influencing the elderly, great demands are made on health care resources, services and personnel. Specially, trained caregivers are a necessity in the care for the elderly, since ageing is accompanied by many changes on a physiological, social and psychological level [7].

Owing to the physiological, psychological and social problems they experience, the elderly often become a burden to their families in the sense that family members are not able to cope with caring for them. As a result, the family often opts for home-based care or institutionalization. Although these options may relieve much of the burden on families, there are challenges.

The purpose of the study was to explore the experiences of the elderly and caregivers in respect of caring for the elderly in Windhoek and Rehoboth Namibia.

\section{Method}

The research design that was selected for this study was qualitative, exploratory, descriptive, contextual and phenomenological in nature.

According to Jackson cited in [8], qualitative research is a broad term used to describe research that is focused on human experience and it involves close contact between the researcher and the participants. In the research field addressed by the current study, very little research has been done on caring for the elderly by caregivers in selected institutions in Namibia, specifically the experiences of the elderly in this regard, as well as the needs of caregivers in these situations. In order for this study to be relevant and applicable in practice, the research was conducted in the context of selected old. The researcher acknowledges the context in which the research takes place in order to understand the surrounding dynamics and systems [9].

\subsection{Target Population}

The group consists of 64 caregivers caring for the elderly in the various old age homes. For this study purposive sampling was used to select the participants. Twenty-six (26) caregivers were identified for the sample out of a 
total of 64 who were available. A total of twenty six caregivers were interviewed. The age group of the caregivers ranges as follows: three (3) were in their twenties; Six (6) were in their thirties; fourteen (14) were in their forties; Two (2) were in their fifties and one (1) was sixty three (63) years of age. All the caregivers were females except for one male. Namibia has thirteen ethnical groups. Most of the caregivers were from the Damara/ Nama a few Coloureds and Oshiwambo community. The experience of caregivers caring for the elderly in old age homes ranges from one year up to twenty years. Twenty nine (29) elderly participated. Twenty one (21) of the elderly were women and eight (8) were men. The age group ranged from sixty (60) to ninety seven (97) years. Ethnical groups of the elderly consist of Germans; Whites, Basters, Coloureds, Nama, Damara Herero and Oshiwambo. The elderly were resident in old age homes from two (2) months up to twenty eight (28) years. Data saturation was reached, after 26 caregivers had been interviewed. Data were collected by using in-depth interviews for both groups of participants. In this study, the researcher was actively involved in the process of collecting data as in [10]. The data collection process consisted of preparing the field, conducting the interviews intended to explore the experiences of the elderly and the caregivers and taking field notes.

\subsection{Conducting Interviews}

Data were collected from in-depth interviews held at the five old age homes in Windhoek, in the natural setting of the participants. Caregivers in the five old age homes were also interviewed in 2009, at a time that suited them including lunch time. Interviews were conducted and the question posed to them was:

"Tell me about your experience of caring for the elderly in old age homes."

Notes taken were read to the participants to verify that they truly reflected what was said and to find out whether any additional information existed. Field notes were taken as well.

Permission was granted by the five administrators of the old age homes to the researcher to conduct the study. Written consent was given by the caregivers and the elderly. The purpose, expectations and the benefits from the study were explained to all groups of the participants.

\subsection{Ethical Measures}

Ethical considerations should encompass the concepts of respect for autonomy (self-determination, confidentiality, privacy and anomymity), non-malificence, beneficence and justice as in [11] [12]. These principles are based on the human rights that need to be protected. Protection of human rights is an ethical responsibility of the researcher, executed by protecting participants "rights". The participants have the right to self-respect, dignity and health. The human rights that require protection in research are 1) self-determination; 2) the right to anonymity and confidentiality; 3) the right to fair treatment; and 4) the right to protection from discomfort and harm as in [10].

\subsubsection{Respect for Autonomy}

The right of self-determination is based on the ethical principle of respect for autonomy. Humans are capable of controlling their own destiny and have the freedom to conduct their own lives [10].

The elderly developmental group represents a group of people who are vulnerable to diminished autonomy. The researcher ensured the protection of autonomy by inquiring from the participants and caregivers whether they were willing to participate in the research [13]. Consent in this context entails agreement to participate in the research as a participant. Free consent can be defined as the voluntary consent of human subjects. Accordingly, the person involved should have the legal capacity to give consent and should be able to exercise free power of choice without any element of force [10]. The researcher explained to the participants that they could withdraw at any time from the research without penalty in [14] [15]. Self-determination was also taken into account by allowing freedom of choice concerning exposure to audio-tape recordings. The elderly and the caregivers were confined to an institution, that is, old age homes, where they stay and worked respectively. In this regard, the researcher was given permission verbally by the various old age homes to conduct the interviews with the elderly and their caregivers.

Furthermore, the caregivers and the elderly gave permission in writing. On initiating phase 1 of the research, the objectives and purpose of the study were explained to the elderly and their caregivers, and this was personalised by conveying how participants might benefit from the outcome of the study. Participants can benefit from the study by the improvement in health care delivery to the elderly as well as improved assessment of their 
health needs and enhanced their self-esteem as a result of special attention [13]. Procedures to be followed to obtain information from these participants were also discussed [10]. It is essential to obtain informed consent from the participants in order to conduct the research.

The anonymity of participants was considered at all time. Concealment of individual identity was assured by concealing the names of participants (i.e. referring to them as participant 1, 2, 3, etc.) and informing participants of the anonymity of their responses. Obtaining permission from participants to use acronyms or changing their names also ensures anonymity.

Anonymity and confidentiality were assured. According to [16], confidentiality is of greater concern than anonymity. The researcher assured confidentiality by making sure that the raw data remained inaccessible to unauthorised persons. The researcher also informed participants, management staff and family members that raw data would not be shared. Confidentiality in terms of content disclosure was not possible; however, it was possible to ensure anonymity.

The researcher assured the right of privacy by interviewing the elderly alone in their rooms because personal information was shared. This information consisted of the beliefs, behaviours and opinions of participants [17].

The researcher always had the responsibility to respect the participants' right to privacy. The private information that was shared by participants was treated confidentially [13].

\subsubsection{The Principle of Non-Maleficence}

This principle encompasses the importance of avoiding harm, or ensuring that as little harm as possible is done in [18]. Consequently, participants have a right to protection from discomfort and harm. The researcher conducted the research in such a manner that the participants were protected from discomfort and harm and their wellbeing was protected. This applies to physical, spiritual, emotional, social and legal protection [13]. In [17], the authors also describe possible sources of discomfort and harm as being physiological, emotional, social and economical. For example, the elderly became tired easily during the interviews and time was allowed to restore their energy. Providing information on the purpose and objectives of the study and the procedures of interviewing provided reassurance and comfort. A safe environment, which created an open atmosphere in which to communicate freely on their experiences also contributed to their comfort.

\subsubsection{The Principle of Beneficence}

Beneficence refers to ensuring that the wellbeing and interests of others are promoted, implying that health care providers act in the best interests of their clients to promote their welfare [18]. Beneficence was ensured by asking participants the right questions, that is, those which would translate into the inclusion of the issues discussed in the formulation of the educational programme. This would then have the potential to bring about positive changes in caregiving.

\subsubsection{The Principle of Justice}

Justice refers to the fair distribution of limited healthcare resources -the benefits and burdens of society should be fairly distributed. Justice is not necessarily reflected by how individuals are treated, but how individuals are treated in the larger context [18]. The participants (the elderly and the caregivers) need fair treatment that is based on the ethical principle of justice. In the past, injustice in subject selection resulted from social, cultural and racial biases in society. While conducting the research, it is expected that the researcher will treat the participants fairly and respect the agreement established between them and the researcher [10]. Justice was assured by accepting responses without judging the content, providing a safe environment which created an open atmosphere, to communicate experiences. This principle includes that the participants had the right to fair selection and treatment. A vulnerable population group is a sub-group of the population that is more likely to develop health problems as a result of exposure to risk factors, or has worse outcomes from these health problems [19]. Elderly people are one of the vulnerable groups that need protection from exploitation. Protection from exploitation also encompasses consent that needs to be obtained-personal consent from participants should be sought and formal consent from guardians or relatives is also required [20]. Purposive sampling ensured that all participants possessed the legal capacity to provide consent and representative insight on caregiving.

\subsection{Permission}

Institutional permission was obtained from the Postgraduate Research Committee of the University of Namibia. 
Approval for the study was given telephonically and verbally by the five old age homes in order that the researcher would not be delayed. Written consent was given by both the elderly and their caregivers.

\section{Results of Interviews}

\subsection{Central Story Line of the Elderly and the Caregivers}

The elderly experience poor interpersonal relations and inadequate attendance to their basic human needs. Caregivers also experience challenges in terms of interpersonal relationships with the elderly, as well as a lack of support from their management in rendering proper care to the elderly. Accordingly, this is the central story line that emerges from the data analysis, and it will be discussed next. Themes and sub-themes obtained from the perceptions of the elderly and caregivers during the data gathering process are reflected in Table 1 . These themes are elicited from concept analyses of the perceptions of the elderly people and their caregivers regarding their experiences of car.

After analysis of the data, the following main themes and sub themes emerged, as seen in the table below.

These themes emerged out of various comments from participants.

\subsection{Main Theme 1: Interpersonal Relationships}

Interpersonal relationships, with sub-themes of character of the participants and communication and language have emerged as important entities in the caring process. In this study, positive and negative experiences concerning interpersonal relationships emerged. In the next sessions, detailed discussion of these themes is provided. Perseverance, patience and respect were viewed by participants as positive characteristics of interpersonal relationships, while stressful behaviour, temperament and confusion as negative behaviour. Caregivers stated the following:

"You will tell them not to put plates in the room but you will find the plates in rooms. One needs to have perseverance".

"One very difficult grandma insults us and accuses us of stealing her things"

"[The Lord is important in my life. He gives me strength and perseverance.]"

"[The elderly need a lot of attention. You need patience and perseverance.]"

Table 1. Identified themes and sub-themes on the elderly and caregiver.

\begin{tabular}{|c|c|}
\hline Main themes & Sub-themes \\
\hline $\begin{array}{l}\text { 1) Interpersonal relationships } \\
\text { were viewed as an important } \\
\text { part of the caring process. }\end{array}$ & $\begin{array}{l}\text { Positive and negative experiences by elderly and caregivers concerning the following: } \\
\text { - Perseverance, patience and respect were viewed by participants as positive } \\
\text { characteristics of interpersonal relationships, while stressful behaviour e.g. poor } \\
\text { temperament and confusion were regarded as negative behaviour. } \\
\text { - Communication and languages are important aspects of quality caring, for example: } \\
\text { shyness, disrespect and aggression were all viewed as negative. }\end{array}$ \\
\hline $\begin{array}{l}\text { 2) The activities involved in } \\
\text { basic physical care were viewed } \\
\text { as important support for the } \\
\text { caring process. }\end{array}$ & $\begin{array}{l}\text { Positive and negative experiences concerning physical care included issues such as } \\
\text { - } \text { Personal hygiene. } \\
\text { - Wound care. } \\
\text { - Taking medication. } \\
\text { - Exercise. } \\
\text { - Adequate nutrition. }\end{array}$ \\
\hline $\begin{array}{l}\text { 3) A support system in a } \\
\text { conducive environment is } \\
\text { needed for the caring process. }\end{array}$ & 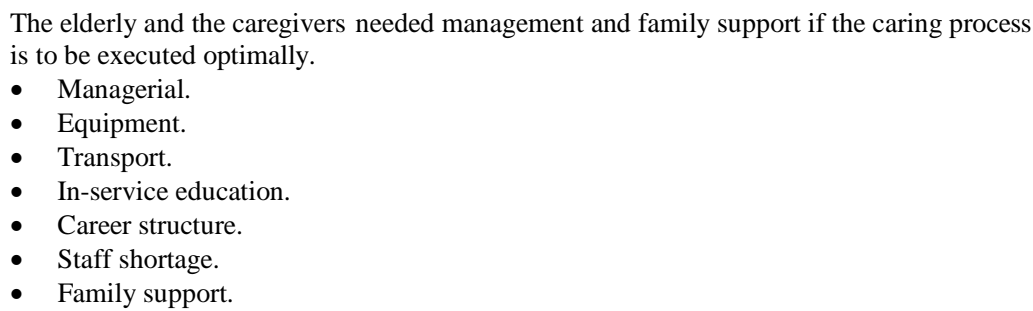 \\
\hline
\end{tabular}




\subsubsection{Patience}

Patience means the capacity to endure delay or provocation without becoming angry or upset [21]. In that regard, the caregiver participant implied:

"Sometimes you become angry with the old people."

"You must have patience and respect. To do a full wash is difficult during wintertime, because it is too cold."

"Others will say I will not be washed by a small child. But you can't stay angry with them for the entire day."

"Sometimes the old people are stubborn."

The following quotes are evidence to that:

"I have a difference of opinion with the workers, we speak again the following day."

"There is one girl who does not know how to speak to old people."

"The workers do not treat us with the respect due to old people. Sometimes they shout at us."

\section{Discussion on Communication}

Communication and language are important aspects for quality caring. The following sub-themes of communication are describe below for example shyness, disrespect and aggression According to [22], communication is the activity or process of expressing ideas and feelings or of giving people information; it is the act of talking to others, particularly in terms of imparting news or information Communication is described as the matrix of thought and relationships between people [23] in this regard some elderly comment. In a study conducted by [24] [25] on communication, it was indicated that more than $50 \%$ of stroke survivors had speech and language impairments and that caregivers lacked the skills to communicate effectively with patients. It was recommended that tailored approaches to communication-enhancement education may be necessary Brown \& Levison, (1987) in [25].

On the other hand, the elderly also had their remarks about the communication they receive

\subsubsection{Shyness}

Shyness results in a lack of communication between the elderly and the caregiver. The elderly fail to communicate their needs; for example informing the caregivers when they are ill.

A caregiver had this to say on shyness.

"My experience is that the first day when the old people are brought to the old age home they feel shy, heartbroken and reserved. If you have a love for your work you will have respect and patience."

Elderly stated.

"My pastor got me this place here, when I lost my house. In the beginning I felt hopeless and shy."

Shyness is a personality trait that produces behaviors ranging from feeling uncomfortable at a party to an extreme fear of being watched by others [26].

\subsubsection{Aggressiveness}

Aggressiveness can also be evidenced as disrespect. In [21], it defines aggressive as the readiness, or having a tendency, to attack or to do harm to others. According to [27], emotion can be defined as a mental and physiological state associated with feelings, thoughts and behaviour.

Caring for the elderly is not easy; sometimes they are unwell and do not want to cooperate and say nasty things to the caregivers.

"We have good and bad days. I also received a smack from an elderly woman. It was about a blue nighty that she wanted to put on but there was no blue nighty. So I took all her clothes out to show her. After the smack I just had to swallow and go on working."

\section{Discussion on Aggressiveness}

Physiological changes occur in all body systems with the passing of time, for instance a loss of auditory neurons occurs, which can lead to hearing loss and can be the reason why elderly people speak too loudly [19].

\subsubsection{Concluding Remarks of Interpersonal Relationships}

Interpersonal relationships were viewed as being an important part of the caring process. Perseverance, patience and respect were viewed as positive characteristics of interpersonal relationships as these qualities can positively 
influence the type of care rendered. On the other hand, negative behaviour, such as aggression, bad temper and confusion can negatively influence quality care. Lack of good communication skills and language can be hindrances to quality care.

\subsection{Main Theme 2: Basic Physical Care}

Basic physical care, with sub-themes of personal hygiene, wound care, taking of medication, adequate nutrition and exercise, were viewed as the supporting activities of the caring process.

Stoyle, (1992) in [28], defines "caring” as a combination of putting feelings into practice and the knowledge and skills to allow someone else to live as independently as possible. Care can be either good or bad care.

Some of the elderly indicated that carers sometimes neglected to attend to their basic physical needs:

"We do not have a nurse who cares for us. If we become sick we have to go to the hospital ourselves."

"The caring is not perfect."

Therefore the elderly stated:

"There are people here that wash you, that are not so good so for $80 \%$...!"

"The care is not so perfect; sometimes I don't want to wash because I am not feeling well."

In that regard, the caregivers stated:

"Elderly people must be bathed in the morning. Their nails, feet and ears need to be checked. Underwear must be checked to see if it is clean. Check the bedding. But the elderly maintained that they do not receive good care as they were quoted saying."

"Some caregivers say this is not in my job description. They don't help the elderly to exercise. Simply get them out of the rooms to come to the dining hall."

The results revealed that elderly people often experience that carers' neglect to care for their basic human needs. Maintaining good personal hygiene is an essential part of caring for an elderly person and it enhances a person's physical and mental wellbeing [29]. However, a carer, you should be aware that when a person becomes dependent on another person for personal hygiene, they can experience a deep loss of independence and self-esteem, which can lead to agitation and depression. In most cases, it is best to help the person with personal hygiene rather than do everything for them [30].

Good caring requires an imaginative approach; it also entails looking after somebody, such as assisting with toilet and other essential hygiene activities, as well as listening to someone's troubles. A qualitative exploratory study was done in Gauteng in South Africa prevailing the health needs of elderly people living in old age home. Three main data sets emerged, namely physical and psychological needs as well as social relationship [31].

\subsubsection{Wound Care/Dressings}

A wound is a disruption in the continuity of tissue and wound healing is the restoration of that continuity.

In that regard the elderly indicated the following:

"My right leg was amputated. The dressing was not done regularly."

"I have had a flesh wound, cancer on my right leg, for six years. I clean the wound myself.]"

Statement from the caregivers also supports the elderly's concern as regard wound care. In that regard, the caregivers stated:

"I did not receive any training. I would like to be trained in wound care, treatment of bedsores, emergency care, injections and mouth care.”

"Caregivers need training in wound care, bedsore emergency care, injections and mouth care. Administering injections does not fall in the scope for caregivers. All these procedures are discussed in the educational programme."

\section{Discussion on Wound Care}

Literature indicates that if dressings were not done regularly it can lead to infection and tissue death. This can cause gangrene to set in and the person's leg then has to be amputated [32]. The following are some of the causes of wounds: 
- Pressure, friction, which result in pressure sores.

- Injuries, such as cuts.

- Thermal wounds caused by extreme cold or heat.

- Chemical wounds-acid on skin.

- Operation wounds.

- Closure of arteries resulting from blood clots, which can cause gangrene [33]. The following section contains a discussion on the taking of medication.

\subsubsection{Taking of Medication}

Some elderly find it difficult to drink their medications. They say they are healthy and do not have to drink any medication. Caregivers stated the following;

"Some elderly people find it difficult to drink their pills. Some say that they are healthy and do not have to drink pills."

Elderly stated:

"My sugar level was high. Doctor treats me with 45 units of insulin in the morning and 20 units at night. I inject myself and sometimes one of the caregivers helps me."

\section{Discussion on Medication}

Medicine is chemical and biological substances are administered to a person in order to prevent and treat diseases. Medicine has the ability to cure, prevent and/or manage symptoms of certain diseases but can also have side-effects. Studies have shown that the elderly may respond differently to younger people. In addition, there is a direct correlation between age and the number of drugs prescribed [34]. Reference [35] reveals that progress is made on primary health care and family medicine in several countries. Many countries accept that primary care is a solution to their structural problem.

\subsubsection{Exercise}

The caregivers complained that the elderly did not want to do exercise. However, elderly people are prone to falling and disease, a weak posture, balancing problems and rheumatoid problems and medication play a big role.

One caregiver stated:

"The elderly are stubborn and do not want to do exercise".

"We need training in how to give exercise."

\section{Discussion on Exercise}

Physical activities are important for people's physiological and psychological welfare. Exercise for those older than 60 is beneficial in building muscle, which helps with posture and balance. Flexibility, strength and cardiovascular endurance are all enhanced with regular physical activity. Bodies weaken with age, but with specific exercise for the elderly one can relieve joint aches and help them feel stronger [36].

\subsubsection{Nutrition}

Nutrition is a very important aspect in everybody's daily lives and for the elderly in particular. Nutrition means the process by which living organisms obtain food and use it for growth, metabolism and repair.

This is evident from the following statements of the elderly:

"We are four elderly people suffering from diabetes. We do not get our special diets. We eat what they serve us."]

The caregiver indicated:

"The elderly usually complain that they eat too early. I have brought this concern under the new pastor's attention. To change the time to 7 and 10 o'clock to give a snack for the Diabetic patients."

\section{Discussion on Nutrition}

Numerous researches have been conducted on the role of dietary factors in various non-communicable diseases, 
such as diabetes, cancer and heart disease [37]. Caregivers should have knowledge of the types of foods that are good for the elderly.

In the process of becoming old, the chances of developing chronic diseases like diabetes mellitus and hypertension are greatly increased. Caregivers need to have knowledge of these diseases, as well as of special diets.

The results indicated that the elderly participants were provided with insufficient nutrition, while caregivers also experienced some challenges in feeding the elderly. Some of the elderly suffer from diabetes mellitus, which requires a special diet.

\subsubsection{Concluding Remarks on Basic Physical Care}

Basic physical care was viewed as important supportive activities for the caring process. Some of caregivers had not received any formal training in the basic caring needs of the elderly. These needs were identified as follows: personal hygiene, wound care, taking of medication, exercise and nutrition. Accordingly, it is important to develop an educational programme for caregivers to ensure quality care

\subsection{Main Theme 3: Managerial Support Is Needed}

Support of management and family, with sub-themes of equipment, transport, in-service education, and career structure and staff shortages also emerged as a concern for the caregivers.

According to [38], South Africa experiences the same problems. Many elderly people are unable to support their housing, water, electricity, health and transport. South Africa is one of three countries on the African Continent which provide a pension of R1, 140. One of the biggest concerns for the elderly in South Africa is their health; nevertheless, healthcare right medication, as well as the fact that some doctors and nurses are illequipped and under-trained to deal with the frail.

One care giver stated. "The time you work is good. If you do something wrong you must go. I have done a private job for some elderly and they rewarded me but it resulted in a disciplinary hearing."

\subsubsection{Discussion on Managerial Aspects}

For [39], support means to help and encourage, providing for or maintaining by supplying. It can be moral, psychological, financial or material and, by showing or saying that you agree, it also meant to give or be ready to give. Managerial support is important so that the old age home can function effectively and smoothly. The work cannot be done if there are not enough staff, finance or equipment.

\subsubsection{Equipment}

Caregivers complain that there is always a shortage of bandages, medicines, ointment and antiseptics and this prevents them from doing their work correctly.

Most of the old age homes in Windhoek are not sponsored by the government but by church organisations and public donations.

The following statement is evidence to it.

"We need during winter equipment like dressings, bandages wintergreen ointments disinfectant like dettol, savlon."

\subsubsection{Transport}

The elderly also experience transport problems, especially in the case of emergencies.

Elderly people had this to say:

"Transport is here, but not for our use."

\subsubsection{Discussion on Transport}

The elderly need someone to be in charge of the old age home at all times, as emergencies may occur during the night. Transport is a problem in some of the old age homes; when there is an emergency an ambulance is generally called. Therefore, mobility becomes a fundamental prerequisite for participation in social relations and activities [40].

Elderly people experience transportation issues since not all elderly people are able to retain their vehicles due to the expense of upkeep and fuel, as well as possible vision problems. Not all senior citizens are located on a 
bus-line. Some must walk or depend upon family or friends. Health concerns (such as limited mobility, arthritis, vision and/or hearing problems) may hinder the everyday tasks which many of us take for granted. Elderly people need transport for everyday activities or tasks include grocery shopping, bathing, grooming and housekeeping, cooking and budgeting (The problems elderly people face, [41].

\subsubsection{In-Service Education}

In-service training is defined as education to help individuals to develop their skills in a specific area of employment after they have started work.

In-service education and training in basic hygiene is needed to

One caregiver stated the following:

"Further training is important. We do a very important work so that we can strive to a diploma and not only a certificate. We work so long we can be upgrade. I have learned to speak German."

If caregivers are not trained and have no knowledge to do procedures correctly, it may lead to serious consequences like physical harm, abuse and death to control any dangerous practices within the work environment to prevent harm to the employees in accordance to the [42].

\subsubsection{Career Structure}

Most caregivers want to climb the career ladder; they want promotion and an increase in salary, benefits such as a housing allowance, a medical fund and a bonus. Some elderly homes have these benefits, others not. Most caregivers are married with a family to support. Moreover, most care for the elderly as it were a calling. The following statements are evidence of this:

"Further study is important. We deliver very important work to strive for a diploma and not only a certificate. We work for so long and need to be upgraded."

\section{Discussion on Career Structure}

A study conducted by [43] focused on the quality and nature of boundaries of care in the relationship between caregivers and the elderly within the home context. It was found that the location of care and the concept of the home in terms of geographical and metaphorical meanings was also a crucial factor in caring.

\subsubsection{Staff Shortages}

Most of the caregivers indicated that they had to work long shifts owing to a shortage of staff.

One caregiver indicated.

"You have to listen to every one's problems. Your work influences family life. There is not enough money to appoint more personnel."

"Finance is difficult; there is a shortage of staff. You have to stand in, no chance to turn around."

\subsubsection{Discussion on Staff Shortage}

Accordingly, their family life is also affected. If there is a family gathering they have to work, [44] maintain that when demands are high, overtime has to be worked in an attempt to make the system work. One is therefore always in a dilemma and end up sacrificing one's family life.

A study conducted by [45] investigated the cost of high staff turnover in long-term care facilities. The report includes direct and indirect cost. Direct cost can be a total of about \$2,500 per loss for each worker, including hiring temporary staff or paying overtime wages to the current staff, advertising, interviewing and background checks and training of new staff.

\subsubsection{Elderly and Caregivers Experience Lack of Family Support}

The participants complained that once the elderly are admitted to the old age home the family forget about them.

The elderly indicated that they needed the support of their families.

This is evident from the following statement:

"The children cannot look after us. I am from Maltahöhe in Namibia."

"I don't have family here that will visit me." 
Positive comments were also made by elderly participants:

I have two children whom i appreciate. My daughter visits me at five.

Negative remarks from caregiver's participant regarding family support:

"If children do not visit the elderly start packing their things and they want to go home. It is very important for children to visit. Then we had to comfort them until they cool down."

\subsubsection{Discussion on Family Support}

Reference [46] suggested that the care of elderly parents should be discussed by everyone in the family, with the entire family being involved in making caregiving decisions that are in the best interests of the elderly parent as well as all caregivers. The experience of rejection can lead to a number of adverse psychological consequences such as loneliness, low self-esteem, aggression and depression. It can also lead to feelings of insecurity and a heightened sensitivity to future rejection in [47] [48]. The experience of being rejected is subjective for the recipient, and it can be perceived when it is not actually present. Although humans are social beings and some level of rejection is an inevitable part of life. Nevertheless, rejection can become a problem when it is prolonged or consistent, when the relationship is important, or when the individual is highly sensitive to rejection. Rejection by an entire group of people can have especially negative effects, particularly when it results in social isolation [49].

Worldwide, the elderly are neglected by family members. The United Nations declared 1999 as the International Year of Older Persons and requested the nations of the world to look after their older people [50]. If families don't have an elderly person, they can adopt one. Remember, we will all grow old one day. The responsibility to sustain the elderly with an allowance should be realised. In other words, this should be viewed as a responsibility and not an act of charity. This will enable the elderly to live in pride and dignity [51].

\subsubsection{Concluding Remarks on Managerial Support}

Caregivers need support from management to render quality care. Management is important in order for the following areas of the caring process to be executed optimally: equipment, transport, in-service education, career structure and staff provision which can all be barriers to the provision of quality care.

\section{Conclusions}

The results of the interviews indicate that the elderly have been treated with disrespect and ineffective physical care.

Interpersonal relationships are an important part of the caring process. Characteristics such as perseverance, patience and respect can positively influence the type of care rendered. Negative behaviour, such as aggression, bad temper and confusion can negatively influence quality care. Lack of good communication skills and language can be hindrances to quality care.

Caregivers have to undergo training in basic physical care of the elderly. The physical and mental wellbeing of the elderly are enhanced.

Managerial support is important for old age home to function effectively and smoothly. The work cannot be done if there are not enough staff, finance or equipment.

In addition, the caregivers also need training on wound care, proper nutrition and handling of emergency cases like epilepsy and asthma.

\section{Recommendation}

Key recommendations are made with regard to the objective exploration and description. It is recommended that an environment that is conducive to quality care for the elderly should be established. Such an environment can be established by managers of the geriatric units where the elderly are cared for. Managers should plan and facilitate regular in-service training and education sessions [27]. Experts on different aspects of the ageing process and the care and treatment thereof can be invited to address the caregivers.

\section{Acknowledgements}

The study was conducted with the permission of the different old age homes as well as the caregivers and elderly 
persons. Special vote of thanks: all elderly and caregivers who share their experiences of caring for the elderly.

\section{References}

[1] Patton, M.C. (2002) Qualitative Research and Evaluation Methods. 3rd Edition, Sage, Thousand Oaks.

[2] Brown, K. (2006) Work Place Law Competence Survey-Definition of A Competent Health and Safety Person. Work Law Network.

[3] The Problems Elderly People Face. Thesaurus Dictionary. (n.d.) http://www.google.com.na/search?Q=Transport+problem+inelderly+in+old+age+homes=en8u

[4] Watson, M. (2006) Respect Is a Two-Way Thing... If Respect Is Given I Give Respect Back. Western Mail, Cardiff.

[5] Samchar, K., Ahmedabad and Gandhingar (2010) Our Elderly. Motilal Anand Vaishnavi.

[6] Flori, D.E. (2013) Care Giving for the Elderly. United Kingdom. http://www.aamf

[7] Clarke, M.J. (2008) Community Health Nursing: Advocacy for Population Health. 5th Edition, Prentice-Hall, Upper Saddle River.

[8] Serafin, J. (2010) How Often Should Elderly Bath. http://wwwcaringbathcom/how-oftenshould-elderly-bath

[9] Guinn, M.J. (2004) A Daughter’s Journey Promoting Geriatric Self-Care: Promoting Positive Healthcare Interactions. Geriatric Nursing, 25, 267-271.

[10] Burns, N. and Grove, S.K. (2005) The Practice of Nursing Research: Conduct, Critique \&Utilization. 3rd Edition, W.B. Saunder, London.

[11] Beauchamp, T.L. and Childress, J.F. (2001) Principles of Biomedical Ethics. 5th Edition, Oxford University Press, Oxford.

[12] Earle, S., Lloyd, C.E., Sidell, M. and Spurr, S. (2007) Theory Research in Promoting Public Health. Sage, London.

[13] Brink, H., Van Der Walt, C. and Van Rensburg, G. (2006) Fundamentals of Research Methodology for Health Care Professionals. 2nd Edition, Juta, Cape Town.

[14] Cormack, D.F.S. (1997) The Research Process in Nursing. 3rd Edition, Marston, Abingdon.

[15] Khosravani, S., Manoochehri, H. and Memarian, R. (2005) Developing Critical Thinking Skills in Nursing Students by Group. The Internet Journal of Advanced Nursing Practice, 7, 3.

[16] Goman, G.E. and Clayton, P. (2005) Qualitative Research for the Information Professionals: A Practical Handbook. 2nd Edition, Facet, London.

[17] Levy, S.R. and Killen, M. (2010) Intergroup Attitudes and Relations in Childhood through Adulthood. Oxford Press, New York.

[18] Dhai, A. and McQuoid-Mason, D. (2010) Bioethics, Human Rights and Law, Principles and Practice. Juta Academic, UK. http://www.amazon.co.uk

[19] Stevans, J.A., Hasbrouck, L.M., Durant, T.M. and Dellinger, A.M. (2004) Surveillance for Injuries and Violence among Older Adults. Morbidity and Mortality. Weekly Report, 48, 27-50.

[20] Gillham, B. (2005) Research Interviewing. The Range of Techniques. Open University Press, Poland.

[21] Thesaurus Dictionary. (n.d.) Angry. http://www.google.com.na/search?Q

[22] Hughes Amani. Elderly in South Africa. Noah Abeacon of Hope. Cape Chameleon. Current Issue Number 13.

[23] Kgomotso, Q.M. (2009) Adherence and Non-Adherence to Antiretroviral Treatment in HIV Positive People in Port Elizabeth: Faculty of Health Science Nelson Mandela Metropolitan University. www.nmmu.ac.za/.../Kgomotso\%20Quentinne\%20Masokoane.pdf

[24] Mills, S. (2003) Gender and Politeness. Cambridge University Press, Cambridge. http://dx.doi.org/10.1017/CBO9780511615238

[25] Mogotlane, S.M., Manaka-Mkwananzi, I., Makoena, J.D., Chauke, M.E. and Young, A. (2004) Juta’s Manual of Nursing Volume 2: Practical Manual. Juta and Geriatrics, Cape Town.

[26] Carducci, B. (2000) Shyness. The New Solution. Psychology Today. http://cms.psychologytoday.com/articles/index.php?term=PTO-20000101-000032

[27] Stanhope, M. and Lancaster, J. (2006) Foundations of Nursing in the Community. Community-Oriented Practice. Mosby, St Louis.

[28] Dolon, D. and Holt, L. (2000) Accident and Emergency Theory in to Practice. http://www.google.com.nal\#htl=en\&source=hp\&stoyle+1

[29] Smith, K.V. and Godfrey, N.S. (2002) Being a Good Nurse and Doing the Right Thing: A Qualitative Study. Nursing 
Ethics, 9, 301-312.

[30] Holtzblatt, K., Wendell, J.B. and Wood, S. (2005) Rapid Contextual Design: A How-To Guide to Key Techniques for User-Centered Design. Morgan-Kaufmann, San Francisco. http://www.articlesbase.com

[31] Chabeli, M.M. (2003) Health Care Needs of Older People Living Permanently in a Residential Home Setting in Gauteng. Department of Nursing Rand Afrikaans University, Johannesburg

[32] Cawthorne, A. (2008) Elderly poverty. The Challenge before Us. http://www.americanProgress.org/about.us/staff/cawthorne alexandra.html

[33] Mollenkopf, H. and Marcellino, F. (2005) Outdoor Mobility and Social Relationships of Elderly People. Archives of Gerontology and Geriatrics, 24, 295-310. http://dx.doi.org/10.1016/S0167-4943(97)00781-4

[34] Chang, C.M. (2005) Use of the Beers Criteria to Predict Adverse Drug Reaction. http://www.medscape.com>Pharmacotherapy>Research

[35] Soanes, C., Hawker, S. and Elliot, J. (2005) Pocket Oxford Dictionary. 10th Edition, Oxford University Press, Oxford.

[36] Jooste, K. (2003) Leadership in Health Service Management. Juta, Lansdowne.

[37] McDougall, P., Hymel, S., Vaillancourt, T. and Mercer, L. (2001) The Consequences of Childhood Rejection. In: Leary, M.R., Ed., Interpersonal Rejection, Oxford University Press, New York, 213-247. http://en.wikipedia.org/wiki/socialrejectioncite-ref-mcdougall.2c-p2001-pp213-2471-0

[38] Hurd, J. (2007) What Exercises Are Suitable for Elderly People... You Need to Know. http://www.articlesbase.com/health-articles/what-exercises-are-suitable-for-elderly-people-you-need-to-know-148945. html\#ixzz18SQ42gOt

[39] Hornby, A.S. (2006) Advanced Oxford Dictionary. 7th Edition, Oxford University Press Inc., New York.

[40] National Planning Commission (1997) OPCIT Midterm Report Review. NDP: Report.

[41] Thesaurus Dictionary (n.d.) Patience. http://www.google.com.na/search?Q

[42] Department of Labour Occupational Safety Health Administration.

[43] McGilton, K., Soren-Peters, R., Sidane, S., Rochon, E., Boscart, V. and Fox, M. (2010) Focus on Communication: Increasing the Opportunity for Successful Staff-Patient Interactions. International Journal of Older People Nursing, 6, 13-24.

[44] Baldwin, J.R. and Hanel, P. (2003) Innovation and Knowledge Creation in an Open Economy. Canadian Industry and International Implications. Press Syndicate, Cambridge University, Cambridge. http://dx.doi.org/10.1017/CBO9780511510847

[45] Tanner, E. (2004) Chronic Illness Demands for Self-Management in Older Adults. Geriatric Nursing, 25, 313-317.

[46] Burress, L. (2008) How to Care for an Elderly Parent.

[47] McGarry, J. (2009) Relationship between Nurses and Older People within the Home: Exploring the Boundaries of Care. International Journal of Older People Nursing, 5, 265-273.

[48] Lindeberg, S. (2010) Food and Western Disease: Health and Nutrition from an Evolutionary Perspective. WileyBlackwell, Chichester.

[49] Williams, K.D., Forgas, J.P. and Von Hippel, W. (2005) The Social Outcast: Ostracism, Social Exclusion, Rejection, and Bullying. Psychology Sydney Press, Sydney, 366 p.

[50] Common Chronic Conditions in Ageing at Home (2010). http://www.parentgiving.comElder-care/common-chronic-condition

[51] Schneider, Z., Elliott, D., Wood, G.L. and Haber, J. (2003) Nursing Research. 2nd Edition, South Woods Press, New Zealand.

[52] Encarta Dictionary: Caregiver North America Accessed (08/09/2009) www.Encartadictionary.com-aboutcom

[53] Goodheart (2010) What Is Hospice and Palliative Care? Health Care Plus, Corporation Northwest WY. Palatine, 1L60067. Poverty, Independence and the World’s Older People. Earthscan, London.

[54] Pusari, N.D. (1998) Eight "Cs” of Caring: A Holistic Framework for Nursing Terminally Ill Patients. Contemporary Nurse, 7, 156-160. http://dx.doi.org/10.5172/conu.1998.7.3.156

[55] Bandman, E.L., and Bandman, B. (1995) Nursing Ethics through the Life Span. 3rd Edition, Appleton \& Langa, Norwalk.

[56] Leedy, P.D. and Ormond, J.E. (2001) Practical Research Planning and Design. 7th Edition, Prentice Hall, Upper Saddle River.

[57] Smith-Nonini, S. (2010) Healing the Body Politic. Rutgers University Press, New Brunswick.

[58] Reid, K. (2013) Care for the Elderly Critical. Windhoek Observer. 
http://observer24.com.na/national/1082-care-for-theelderly-critical

[59] Arthur, D., Pang, S. and Wong, T. (2011) Evidence for Caring Behaviour.

[60] Encarta Dictionary: Elderly Accessed (08/09/2009). North America. www.Encartadictionary.com-aboutcom

\section{Appendix}

\section{Caregiver}

Reference [52] defines a caregiver as somebody who has the principal responsibility of caring for a person. Accordingly, a caregiver or carer is someone who provides assistance to another person who cannot live fully independently owing to physical, psychological or mental disability. Caregivers may have duties which are fairly light, such as stopping by someone's house every few days to tidy up, or the duties may be more involved, such as living with someone to provide constant assistance with a variety of tasks. Both volunteer and paid caregivers work all over the world [53]. Both the elderly and caregiver exist in society and are exposed to many processes which influence their behavior. They also have the freedom to make choices about their lives [54].

\section{Caring}

The concept of "caring” is the rubric or the frame within which all caring activities occur. These activities should be moral and centered on the wellbeing of humans in [55] [56].

Roach in [57] describes 5c's of caring as the following: compassion, competence, confidence, conscience and commitment which are needed for every carer. [58] added another 3c's for caring as courage, culture and communication. This is to render a holistic care which encompasses physical, psychological, emotional, spiritual and cultural aspects. A study was done on 77 Hong Kong student nurses. A study done by [59] highlighted compassion and competence as their major features and it suggested that methodological problems may have inhibited a deeper analysis of their caring attributes and behaviour.

Reference [7] indicated that the term "caring” refers to and means persons, events, projects and all the things that matter to people. Caring covers a range of involvements,

\section{Elderly}

The ageing process is of course a biological reality, which has its own dynamics, largely beyond human control. However, it is also subject to the constructions by which each society makes sense of old age. In the developed world, chronological time plays a paramount role. Reference [60] explains an elderly person as someone past middle age and approaching the later stages of life. The age of 60 or 65, roughly equivalents retirement age, in most developed countries is said to be the beginning of old age. In many parts of the developing world, chronological time has little or no importance in the meaning of old age. Other socially constructed meanings of age are more significant such as the roles assigned to older people. In some cases, it is the loss of roles accompanying by physical changes, which is significant in defining old age. Thus, in contrast to the chronological milestones which mark life stages in the developed world, old age in many developing countries is seen to begin at the point when active contribution is no longer possible [16].

\section{Experiences}

Experiences describe exposure to, or having observed certain facts or events.

\section{Old Age Home}

An old age home is an institution where 24-hour care for residents is provided by church organisations, social services, voluntary organisations and private individuals. The elderly may have their own rooms or they may share, and they might require help with bathing, washing, toileting and eating Stoyle, (1992) in [28]. 